\title{
The presence of 1-naphthol in the urine of industrial workers exposed to naphthalene
}

\author{
Grażyna Bieniek
}

\begin{abstract}
1-Naphthol at concentrations ranging from 0.4 to $34.6 \mathrm{mg} / \mathrm{l}$ was found in urine collected directly after the end of the work shift from a group of industrial workers employed in distillation of naphthalene oil. The maximum excretion was found one hour after the end of the shift and the mean excretion rate was 0.57 $\mathrm{mg} / \mathrm{h}$. Coke plant workers exposed to naphthalene and other aromatic and polycyclic hydrocarbons also had 1naphthol in their urine. Mean values were $0.89 \mathrm{mg} / \mathrm{l}$ (working with new technology) and $4.86 \mathrm{mg} / \mathrm{l}$ (working with old technology) and the excretion rates were 0.19 and $0.31 \mathrm{mg} / \mathrm{h}$ respectively. The maximum excretion was shifted to two to three hours after the end of the exposure. For non-exposed subjects the mean urinary 1-naphthol concentration was 120 $\mu \mathrm{g} / \mathrm{l}$ and the excretion rate was $7 \cdot 0 \mu \mathrm{g} / \mathrm{h}$.
\end{abstract}

(Occup Environ Med 1994;51:357-359)

1-Naphthol exists in animals as a metabolite of naphthalene. ${ }^{1}$ It is excreted in urine as a sulphate or glucuronide conjugate. ${ }^{2-4}$ Keiser et al found 1-naphthol in the urine of people exposed to the insecticide "carbaryl".

The presence of 1-naphthol was earlier found in urine collected from workers before and after exposure and its excretion seemed to be slowed under conditions of simultaneous exposure to aromatic and polycyclic hydrocarbons. ${ }^{6}$ This study investigates the excretion of 1-naphthol in more detail.

\section{Materials and methods}

The investigations were conducted under industrial conditions. All subjects were smokers.

Four groups of workers were investigated:

Group A: 75 operators exposed to naphthalene and other phenolic compounds during distillation of naphthalene oil.

Group B: 57 coke plant workers exposed to naphthalene, benzene, and other aromatic hydrocarbons, at coke plant I (old technology).

Group C: 66 coke plant workers exposed to naphthalene, benzene, and other aromatic hydrocarbons, at coke plant II (modern technology). In this case samples of air were taken constantly and naphthalene was measured in the air.
Group D: 24 subjects not occupationally exposed to naphthalene. Environmental exposure could not be excluded.

\section{URINE SAMPLING}

Samples of urine were collected as (1) voids of urine directly after the end of the work shift; (2) successive samples of urine collected for 24 hours from 26 workers.

ANALYSIS OF 1-NAPHTHOL IN URINE

The concentration of 1-naphthol in the hydrolysate of urine was determined spectrophotometrically after its separation by thin layer chromatography on polyamide gel with development in chloroform-methanol (99:1 $\mathrm{v} / \mathrm{v}) .^{7}$

Because of low concentrations of 1-naphthol in the urine of occupationally nonexposed workers gas chromatographic techniques were employed on these samples.

Values were corrected for a specific gravity of 1.024 and for creatinine content in the urine.

\section{AIR SAMPLING AND ANALYSIS}

Personal air sampling was performed with a battery operated pump (type AFC123 Casella Ltd, London) connected to a filter holder attached to the shoulder of the subject. Air was aspirated at a flow rate of $0.51 / \mathrm{min}$ through active carbon type H2. The naphthalene was released from the active carbon by treatment with $1 \mathrm{ml}$ carbon disulphide in an ultrasonic bath for 15 minutes.

The content of naphthalene in the air samples was analysed by gas chromatography (Hewlett-Packard model 5890 II) with flame ionisation and a capillary column Ultra 1 (Lusiak T, Siwek A, unpublished data).

The error of the method was about $10 \%$ or higher for low naphthalene concentrations. For concentrations above $5 \mathrm{ng} / \mu \mathrm{l}$ the error was $5-6 \%$.

\section{STATISTICS}

Geometric mean and geometric SD were calculated. Regression analyses were carried out with a program supplied by Statistical Graphics Corporation, US. Toxicokinetic calculations were carried out according to the method of Piotrowski. ${ }^{8}$

\section{Results and discussion}

The table presents values of concentration and excretion rate of 1-naphthol in urine collected directly after the end of the exposure 
Concentrations and the excretion rate of 1-naphthol in urine

\begin{tabular}{|c|c|c|c|c|c|}
\hline \multirow[b]{2}{*}{ Group } & \multirow[b]{2}{*}{$\begin{array}{l}\text { No of } \\
\text { subjects }\end{array}$} & \multirow[b]{2}{*}{$\begin{array}{l}\text { Observed } \\
\text { value (mg/l) }\end{array}$} & \multicolumn{2}{|l|}{ Values corrected for } & \multirow[b]{2}{*}{$\begin{array}{l}\text { Excretion rate } \\
\text { (mg/h) }\end{array}$} \\
\hline & & & Creatinine $(\mathrm{mg} / \mathrm{g})$ & $\begin{array}{l}\text { Specific gravity } \\
1.024(\mathrm{mg} / \mathrm{l})\end{array}$ & \\
\hline C & $\begin{array}{l}75 \\
57 \\
66 \\
24\end{array}$ & $\begin{array}{l}7.48(2.187) \\
4.86(2.465) \\
0.89(1.783) \\
0.13(1.868)\end{array}$ & $\begin{array}{l}4.35(2.734) \\
3.79(2.128) \\
0.93(2.293) \\
0.10(2.514)\end{array}$ & $\begin{array}{l}8.95(2.745) \\
5.53(2.084) \\
1.06(2.502) \\
0.12(2.464)\end{array}$ & $\begin{array}{l}0.57(2.068) \\
0.31(1.954) \\
0.19(2.454) \\
0.007(1.786)\end{array}$ \\
\hline
\end{tabular}

Values are geometric means (geometric SD)

Group $A=$ operators of the distillation of naphthalene; group B = cokers of coke plant I (old technology); group $\mathrm{C}=$ cokers of coke plant II (modern technology); group $\mathrm{D}=$ non-exposed workers.

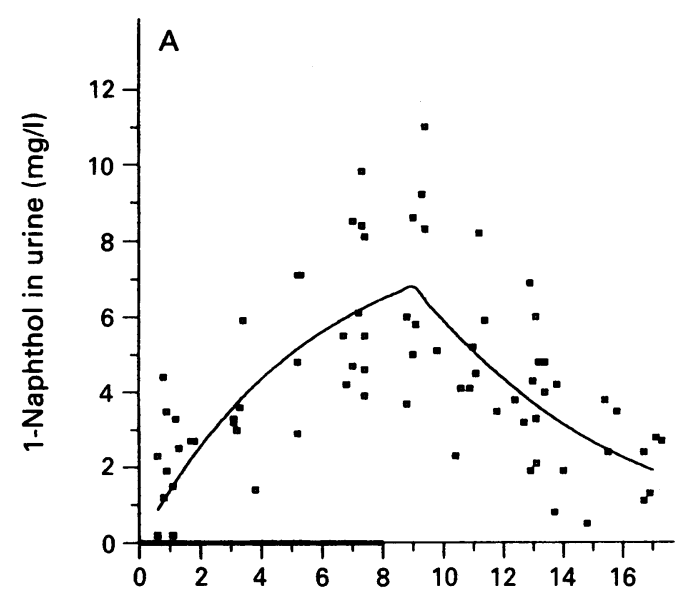

(A), coke plant workers $(B, C)$, and subjects occupationally non-exposed to naphthalene (D). The results were $\log$ normally distributed. Concentrations of 1-naphthol presented in the table were the highest in the operators of the naphthalene oil distillation. This presumably results from the fact that naphthalene is the main component of naphthalene oil (73.6\%).

Figure 1 presents the relation between the average naphthalene concentrations in breathing zone air during exposure and 1-naphthol

Figure 1 Correlation between naphthalene in breathing zone air and 1-naphthol in urine of coke plant workers. Lines and curves are calculated regression line (solid line in centre), $95 \%$ CIs (dotted curves close to regression line), and $95 \%$ CIs of individual samples (outermost dotted lines).

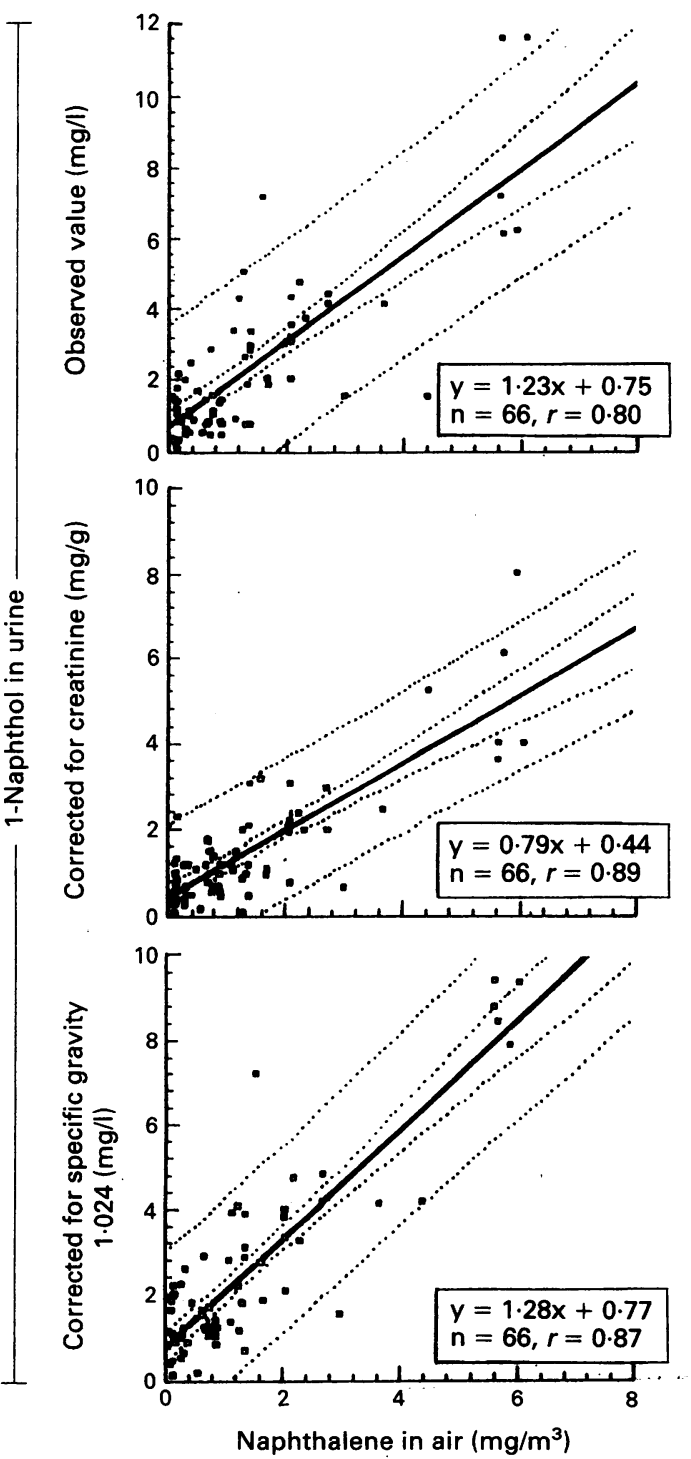

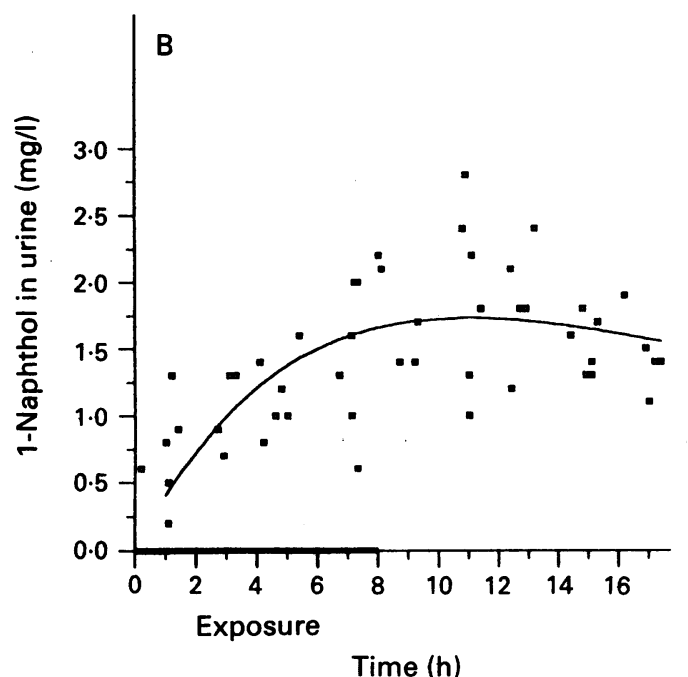

Figure 2 Urinary excretion of 1-naphthol as a function of time. (A) workers employed in distillation of naphthalene oil; regression equation for $t \leqslant 9, c(t)=8.5\left(1-e^{-0.18 t}\right)$; for $t>9, c(t)=8.5\left(1-e^{-0.18 z}\right) e^{-0.18(t-9)}$;

$k=0.18 / \mathrm{h}, t_{1 / 2}=4.0$ hours. (B) Coke plant workers; regression equation, $c(t)=4.5\left(e^{-0.05 t}-e^{-0.15 t}\right) ; k_{1}=$ $0.05 / h, t_{1 / 2}=14.0$ hours; $k_{2}=0.15 / h, t_{1 / 2}=4.6$ hours. $c=$ concentration of 1-naphthol in urine; $t=$ time from the start of exposure.

concentration in the urine of coke plant workers (group C) collected just after the end of the work shift. A linear dependence between the time weighted average naphthalene concentration in the air and 1-naphthol concentration in the urine for the original measured value, corrected for specific gravity 1.024 and corrected for creatinine content, was noted.

The urinary excretion of 1-naphthol as a function of time calculated from the beginning of exposure was examined (fig 2). Figure $2 \mathrm{~A}$ presents data on 1-naphthol excretion in the urine of operators of naphthalene oil distillation during and after exposure. The excretion coefficient $k=0 \cdot 18 / \mathrm{h}$ indicates a half life of about four hours. The presented model gives a similar shape of excretion curves for 1-naphthol as found earlier for phenol. ${ }^{9}$ It is assumed that 1-naphthol in the urine of naphthalene oil operators is the result of exposure to naphthalene as well as low amounts of 1-naphthol which are found in the naphthalene oil. 
In the group of coke plant workers exposed to naphthalene (in the absence of 1-naphthol) the excretion of 1-naphthol in urine (fig 2B) is described by a kinetic equation more appropriate for the "metabolic" model. The kinetic coefficients, 0.05 and $0 \cdot 15 / \mathrm{h}$ may represent the metabolic conversion of naphthalene and rate of excretion, respectively. The numerical values of these coefficients were obtained as the best fits from computer imaging.

A comparison of the time course of 1-naphthol excretion in fig $2 \mathrm{~A}$ and $\mathrm{B}$ may indicate differences between the kinetics of 1-naphthol and naphthalene respectively; naphthalene requires metabolic conversion before excretion. This process may be much slower compared with excretion alone and therefore some accumulation in the body under conditions of occupational exposure to naphthalene cannot be excluded.

For given concentrations of naphthalene in breathing zone air one would expect higher concentrations of 1-naphthol in urine than those obtained in our studies. This may be explained by the relatively low metabolism of naphthalene to 1-naphthol under conditions of simultaneous exposure of coke plant workers to chemical compounds present in large amounts in coal tar.
I am grateful to Professor JK Piotrowski for his assistance in kinetic calculations, $\mathrm{K}$ Klimek, MS for her help with statistical analyses, and Professor T Wilczok for general supervision of the experimental work. I thank the Laboratory of Environmental Protection at Carbochemical Plant "Zabrze" for cooperation during the field study.

1 Sanborn MR, Malins DC. The disposition of aromatic hydrocarbons in adult spot shrimp (Pandalus platyceros) and the formation of metabolites of naphthalene in adult and larval spot shrimp. Xenobiotica 1980;10:193-200.

2 Chern WH, Dauterman WC. Studies on the metabolism and excretion of 1-naphthol, 1-naphthyl- $\beta$-D-glucuronide and 1-naphthyl- $\beta$-D-glucoside in the mouse. Toxicol Appl Pharmacol 1983;67:303-9.

3 Tremaine LM, Diamond GL, Quebbemann AJ. In vivo quantification of renal glucuronide and sulfate conjugaquantification of renal glucuronide and sulfate conjugation of 1-naphthol and p-nitron

4 Redegeld FA, Hofman GA, Noordhoek J. Conjugative clearance of 1-naphthol and disposition of its glucuronide and sulfate conjugates in the isolated perfused rat kidney. F Pharmacol Exp Ther 1988;244:263-7.

5 Keiser JE, Kirby KW, Tremmel E. Reversed phase high performance liquid chromatographic separation of human phenolic metabolites of propoxur (Baygon), carbo-furan and carbaryl. I Chromatogr 1983;259: 186-8.

6 Bieniek G, Bocheńska T, Skorek R, Kustra G, Różanska $R$, Czogala J, et al. The level of selected chemical compounds metabolities in the urine of coke plant workers. Med Pr 1989;40:183-91. (In Polish.)

7 Bieniek G, Wilczok T. Separation and determination of phenol, $a$-naphthol, $m$-, $p$ - and $o$-cresol and 2,5 -xylenol, and catechol in the urine after mixed exposure to phenol, naphthalene, cresols, and xylenols. Br f Ind Med 1986;43:570-1.

8 Piotrowski JK. The application of metabolic and excretion kinetics to problems of industrial toxicology. Washington: US Department of Health, Education and Welfare, 1971

9 Piotrowski JK. Evaluation of exposure to phenol: absorption of phenol vapour in the lungs and through the skin and excretion of phenol in urine. $\mathrm{Br} \mathcal{F}$ Ind Med 1971;28:172-8. 